\title{
THE
}

\section{Keys to person-centred care to persons living with dementia - Experiences from an educational program in Sweden}

\author{
Mia Berglund \\ Catharina Gillsjö \\ University of Rhode Island, cgillsjo@uri.edu \\ Rune Svanström
}

Follow this and additional works at: https://digitalcommons.uri.edu/nursing_facpubs
The University of Rhode Island Faculty have made this article openly available. Please let us know how Open Access to this research benefits you.

This is a pre-publication author manuscript of the final, published article.

Terms of Use

This article is made available under the terms and conditions applicable towards Open Access Policy Articles, as set forth in our Terms of Use.

\section{Citation/Publisher Attribution}

Berglund, M., Gillsjö, C., \& Svanström, R. (2018). Keys to person-centred care to persons living with dementia - Experiences from an educational program in Sweden. Dementia. https://doi.org/10.1177/ 1471301218754454

Available at: https://doi.org/10.1177/1471301218754454 


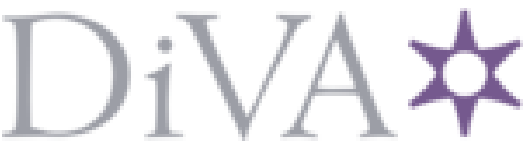

http://www.diva-portal.org

\section{Postprint}

This is the accepted version of a paper published in Dementia. This paper has been peerreviewed but does not include the final publisher proof-corrections or journal pagination.

Citation for the original published paper (version of record):

Berglund, M., Gillsjö, C., Svanström, R. (2018)

Keys to person-centred care to persons living with dementia: Experiences from an educational program in Sweden

Dementia, : 1-15

https://doi.org/10.1177/1471301218754454

Access to the published version may require subscription.

N.B. When citing this work, cite the original published paper.

Permanent link to this version:

http://urn.kb.se/resolve?urn=urn:nbn:se:his:diva-14695 
Keys to person-centered care to persons living with dementia - Experiences from an educational program in Sweden

Berglund, $M^{1 \S}$. Gillsjö, $C^{1,2}$., Svanström, $R^{1}$.

${ }^{1}$ School of Health and Education, University of Skövde, Sweden

${ }^{2}$ College of Nursing, University of Rhode Island, US

${ }^{\S}$ Corresponding author

\section{Correspondence:}

Mia Berglund

School of Health and Education, University of Skövde

Box 408

SE 54128 Skövde, Sweden

Telephone: +46500448000

E-mail:_mia.berglund@his.se

E-mail addresses:

RS: rune.svanström@his.se

CG: catharina.gillsjo@his.se 


\section{Abstract}

Growing old entails an increased risk of disabilities and illnesses such as dementia. The orientation in Sweden on national level is that individuals remain in their own homes if desired and receive person-centered home care. The aim of this study was to describe the experience of an educational program and its influence on daily provision of care to persons with dementia.

A life-world approach was used. Data were collected through group interviews with care providers in the context of home. The findings are presented in five themes: Increased knowledge about dementia and treatment, Relationship-building in order to provide good care, Open and flexible approach conveys calm, Continuity and flexibility are cornerstones in the care and Perceived changes. This person-centered educational intervention resulted in a care that was based on each individual's personality, preferences and priorities in life. Education given with continuity over time is key to improving provision of care to person with dementia.

Keywords: dementia, education, experience, home health care, person-centered care

\section{Introduction}

Life with dementia can be troublesome (Svanström \& Dahlberg, 2004), especially for those who live alone (Svanström \& Sundler, 2015). The needs of person-centered care and continuity in the provision of care to persons with dementia were highlighted in National Guidelines for Care in Cases of Dementia (Socialstyrelsen, 2016). In person-centered care (Ekman et al., 2011), the patient's life situation comes to the forefront, and not the disease 
itself. Furthermore, it is characterized by evolvement of a partnership between the patient family and care provider and listening to the patient's narrative and documenting the patient's story (Ekman et al., 2011). Person-centered care in dementia care (Socialstyrelsen, 2016) points at the need of understanding the person's changed behavior due to disease and, in relation to the person's preferences and values before occurrence of disease. The relatives are often needed to be involved to tell the patient's story. Continuity in care are important, however, the lack of continuity in home care remains in several organizations. This has been highlighted during the past year in Swedish newspapers and television. One example is a story of a man that photographed the care providers visiting his home. Over a short period of time he had pictures of about 70 different persons. Another example is a woman that received visits from 35 different care providers during a period of two weeks. These examples show the importance of studying organizations to find ways of providing person-centered care and increasing continuity in care to persons with dementia

\section{Background}

Growing old involves many changes in life that are associated with an increased risk of illness and disability. Persons in need of health care in Sweden have a right to gain access to health care and social care services that meet their needs and that assure of a reasonable standard of living. This is regulated by legislation in the Social Services Act (SFS, 2001:453) and Health and Medical Services Act (SOSFS, 1982:763) in Sweden. Not uncommonly, the home is the center of life when growing old along with a desire to remain at home as long as possible. Over time the home becomes intimately integrated with the person's identity and way of living (Gillsjö, Schwartz-Barcott, \& von Post, 2011; Gillsjö, \& Schwartz-Barcott, 2011). Additionally, the orientation in health care policies on a national level is that anyone with the desire and 
ability to remain at home should be given the opportunity to receive home health care services (SOU, 2008:51).

Life may change in a radical ways for persons living with health problems, especially dementia. This condition often results in different types of disabilities which tend to increase in the later stages of the disease (Hedman, Nygård, Almkvist, \& Kottorp, 2015; Phinney \& Chesla, 2003; Shanley, Russell, Middleton, \& Simpson-Young, 2011; Slaughter, Eliasziw, Morgan, \& Drummond, 2011; Svanström \& Dahlberg, 2004; Svanström \& Sundler, 2015). Dementia influences daily living and often results in increasing dependence on health care and social services on daily basis. The development of the dementia disease and level of care varies for each person. This address the need of a care that is person-centered and not primarily based on the disease itself. Sometimes, the person is forced to move into a nursing home in the later stages of the disease. The need for care may also affects relatives as spouses and children, who often invest a great amount of time and efforts in caring for the family member with dementia (Li, Cooper, Bradley, Shulman, \& Livingston, 2012; O'Shaughnessy, Lee, \& Lintern, 2010; Shanley et al., 2011; Svanström \& Dahlberg, 2004; Sun, 2014; Wadham, Simpson, Rust, \& Murray, 2016)

In 2012, it was estimated that 158000 persons in Sweden had dementia and more than 90 000 lived at home. The majority of persons living at home with severe dementia live with a spouse or other relatives (Socialstyrelsen, 2014). Persons with dementia in need of continuous health care services seem to have difficulties in expressing their needs of care. Research conducted in Sweden by Sjöbäck (1994) and Rydholm Hedman (2007) indicated that persons 
with dementia are not offered the same amount and quality of healthcare as persons without cognitive impairment.

Home care services for people with dementia most often are not associated with advanced medical treatments. The care is focused on dealing with daily life which includes daily routines, household chores, activities and social interaction. According to the Swedish Agency for Health Technology Assessment and Assessment of Social Services, the cost for these home health care and social services is a major strain on the total budget for the Swedish community based health care (SBU, 2008).

Home care services for persons with dementia is estimated to be 0,5 hours a day on average (Socialstyrelsen, 2014). The most common service offered to persons with dementia, besides home care services is, day care centers for persons with dementia and episodes of short-term care (SBU, 2008).

Does home care service in Sweden respond to the individual needs of persons with dementia and their continuous needs of care? The amount of care given by health care providers and care given by relatives was compared in a study among persons with dementia and their relatives in a rural community (Nordberg et al., 2007). The result showed that the care given by home health care services was on average, one hour per day. Persons with mild dementia received the shortest time of visits from the home health care providers who spent on average up to one and a half hours per day with persons living with severe dementia. Relatives estimated that they, on average, provided care during sixteen hours a day for their family member who suffered with severe dementia. According to National Board of Health and 
Welfare the amount of informal care given by relatives in Sweden in 2012 was estimated to range in between 4, 7 to 6, 6 hours a day (Socialstyrelsen, 2014).

The rather low amount of time for home health care services might in part be explained by extensive time spent in day care centers by persons with dementia. According to the National Board of Health and Welfare (Socialstyrelsen, 2014), persons with dementia enrolled in this type of day care services spend on average 2-3 days a week at these centers. This suggests that health care services offered to persons with dementia with a manifest care need is mainly given in contexts other than home.

An overview of research done in dementia care (SBU, 2008) shows no clear guidance in the provision of care. However, it emphasizes the importance of being aware of the internal culture in the organization including the fundamental view of human beings in the provision of care. It is stressed in The National Guidelines for Care in cases of Dementia that the care should be person-centered and provided by a multidisciplinary team (Socialstyrelsen, 2016). These guidelines emphasize the importance of education, training, coaching and feed-back for care providers who provide care on a daily basis in order to achieve a continuous personcentered care. However, educational needs for other professions throughout the organizations providing health care services should be considered (Svanström, 2009). There are studies that show how to change existing attitudes toward caring for persons with dementia through use of educational programs. Chrzescijanski, Moyle, and Creedy (2007) implemented an educational program to change care providers' perceptions and attitudes toward dealing with aggression from persons with dementia. This program changed the understanding in how the personnel perceived the persons' expression of feelings as 
aggression, reactions and actions. Cooke, Moyle, Venturato, Walters, and Kinnane (2014) implemented a model of care based on capability approach, person-centered, relationshipcentered and strength-based care. They indicated that education is one way to achieve changes as to implement person-centered care in health care. Additionally, they argued the need of support on all levels throughout the organization, including management to establish a change through education. The national guidelines for care in cases of dementia (Socialstyrelsen, 2016) have a direction towards person-centered care and continuity. The question is how this can be implemented in organizations providing care for persons with dementia? Is an educational program a key in the provision of person-centered care? If so, how it is structured and organized? The aim of this study was to describe the experiences of an educational program and its influence on the daily provision of care to persons with dementia.

\section{Settings}

A community in the western region of Sweden known for good institutional dementia care, developed an educational program in order to improve quality of home care services for persons with dementia and cognitive decline. The education program was developed in 2006 by two nurses engaged in institutional dementia care and consisted of a number of four, two and a half hour sessions in periods of four to six months. The education was continuously ongoing during the years 2007-2012 in the community. The content in the educational program was closely linked to the caring context. The program involved all caring professions (care assistants, home care officers, registered nurses, physiotherapists, occupational therapists, and care managers). The first session was about dementia diseases, associated 
disabilities and other related problems. It also included discussions on how to deal with various problematic situations in the provision of care in the context of the home. The goal in this first session was to increase the care providers' understanding and to promote a relationship where the person's individual needs were considered. The second session had a focus on psychiatric nursing tied to actual cases i.e. persons with dementia who were provided home health care. Additionally, there was an emphasis on the relationship and use of conversation as a working method. The aim was to help the care providers to understand the importance of including emotions in the conversation as one way to deepen the relation and capture problems in early stages (c.f. Socialstyrelsen, 2016). The third session was orientated toward the various approach models: support of self-identity (Cohen-Mansfield, Parpura-Gill, \& Golander, 2006), validation (Neal \& Barton Wright, 2003), reorientation and reminiscence (c.f. SBU, 2008). The different models were illustrated by use of actual cases which were examples of persons with dementia in the context of home health care. There was an emphasis on supporting self-identity in an individual way. The fourth session was focused on person-centered care, "how" to tailor and provide individualized care for each person instead of "what" to do in the situation on general basis. Each care provider were asked to reflect, plan, describe and document the provision of individualized care for a person with dementia whom they had personal responsibility. The session contained reflection time and discussions of how the health care providers together could use their new knowledge and find solutions to problems. The importance of dialogues as basis for the relational communion was emphasized. To further develop the care some of the care assistants were included in a network to bring the care further. 


\section{Method}

This study was carried out from a reflective lifeworld approach to support the participants' reflections on their experiences of a phenomenon (Dahlberg, , Dahlberg, \& Nyström, 2008). The phenomenon in this study was "experiences of an educational program". Phenomenological research requires an open and sensitive attitude and the researchers must bridle their understandings. Bridling requires maintaining a critical and reflective attitude throughout the research process (Dahlberg, \& Dahlberg, 2003; Dahlberg, et al., 2008). This involves being aware of one's own pre-understandings and understandings and to obtain attentiveness and openness in delineating and understanding the meanings of the phenomenon that emerged, as well as maintaining sensitivity to the phenomenon.

\section{Data Collection and Participants}

The participants in the educational program were all invited to participate and share their experiences in the study. Data were collected through group interviews (Dahlberg, et al., 2008; Berglund, Sjögren \& Ekebergh, 2012) in which the participants reflected upon their experiences of the intervention and its impact on daily work. Seven group interviews with two to seven participants in each group were conducted with a total of 42 participants. Participants were care assistants, registered nurses, physiotherapists, occupational therapists, care managers, home care officers, politicians, management directors and two of the educators. The participants added description of the phenomenon from their own perspective in range from care providers to decision makers. The researchers $(A, C)$ conducted interviews, together or separately. The interviews started with an open question about their experiences of the education program followed by questions to concretize and deepen the understanding of the 
experience of the phenomenon. All interviews were audio-recorded in total approximately six hours.

Insert table here

\begin{tabular}{|l|l|}
\hline $\begin{array}{l}\text { Number of participants } \\
\text { in each group interview }\end{array}$ & Occupation \\
\hline 6 & Educators, Management directors, Politicians \\
\hline 2 & Home care officers \\
\hline 7 & Care assistants \\
\hline 5 & Care managers \\
\hline 2 & Care assistants \\
\hline 6 & Occupational therapists, Physiotherapists, Registered nurses \\
\hline 6 & Care assistants \\
\hline 6 & Care manager, Care assistants \\
\hline 2 & Care assistants \\
\hline
\end{tabular}

\section{Data Analysis}

The analysis was guided by Krueger and Casey (2009) method for analysing group interviews.

Initially, the researchers $(A, C)$ listened to the interviews, first separately and then together. This was followed by a mutual identification of meaning units in relation to the phenomena. The process of analysis can be described as dialectic with movements between the situation as a whole and the parts. (Dahlberg, et al., 2008). The meaning-units were clustered into different groups and finally five themes emerged that described the participants' experiences of the phenomenon. Then the researchers $(A, C)$ checked the themes in relation to the interviews on their own. In the continuing process the researchers $(A, B, C)$ worked together in describing the content in the themes through a continuous iterative movement between the separate interviews, meaning units, the clustered groups and the themes. In this process, the analysis and emerging meanings were discussed, questioned and critically reflected upon in relation to our pre-understandings with aim to not make the indefinite definite to fast (Dahlberg, \& Dahlberg, 2003). Finally quotations from the interviews were brought into the description of the themes in order to enhance the trustworthiness of the study. 


\section{Ethical Considerations}

The managing director in the municipality gave the permission to conduct the study. According to The Act (2003:460) there was no need of ethical approval from the Regional Ethical Board for Ethical Review of Research Involving Humans (SFS, 2003). The study was conducted according to the Code of Ethics of the World Medical Association (Declaration of Helsinki, 2016) which also included considering the aspect of confidentiality. As a first step written information about the study was given to participants. This document included information about the study's purpose and pointed out the participant's right to relinquish from participation at any time without explanation. Additional information was given and the participants gave their informed consent at the scheduled time for group interview. Sensitivity was shown to each individual participant during the interviews. It was important that the participants felt comfortable and were not harmed.

\section{Findings}

The most significant finding was that care should be based on each care recipient's personality and individual needs. The care changed to be more focused on what was most important to the person, which can be understood as person-centered care. This orientation was expressed by the politicians, managing directors and educators organisational and educational points of views and by care providers from their day-to-day caring perspective. The relationship, flexibility and continuity were described as fundamental preconditions in order to provide individually tailored care for persons with dementia and manifest care needs. The knowledge of the 'healthy' person was important as a basis for this kind of care. One of the care providers described person-centered care as follows: 'Starting with the person's needs, it's as simple as 
that. But when it should be translated into reality, it's a little bit difficult.' The knowledge of the person-centred care was reflected as 'knowledge is situated in the body'. The findings consist of five themes; Increased knowledge about dementia and treatment, Relationshipbuilding in order to provide good care, Open and flexible approach conveys calm, Continuity and flexibility are cornerstones in the care and Perceived changes.

\section{Increased knowledge about dementia and treatment}

The care providers that participated in the education program expressed that they obtained a deeper knowledge and understanding of different types of dementias including specific focus on various caring approaches. The increased awareness that was expressed seemed to have influenced their overall caring approach in caring for all care recipients, 'it's like ripples on the water'. The participants expressed that the concept of 'cognitive impairment' was used more and more since it was perceived as not being as stigmatizing as the word; dementia. The concept seemed to be understood by the participants as signs of symptoms and needs that can be equivalent to problems related to dementia. They expressed that increased knowledge helped them to identify and detect signs of cognitive impairment earlier than they did before the intervention. It seemed that this increased awareness led to a reflective process, which gave the opportunity to think and plan a step ahead in care. They expressed that they knew who to contact in case of problems, and they felt calmer and more secure when they met persons with dementia. The creation of care that consisted of fewer staff around every care recipient gave them the opportunity to put more emphasis on creating good relationships and ability to individualize each caring act. They expressed that they had learned how they could facilitate individualized care in daily life for a person with dementia. An example of this was 
avoiding asking questions that might cause confusion; instead they involved the care recipients in the decisions. For example, instead of asking the question: 'What do you want for breakfast today?' They asked: 'Shall we go to the kitchen and make porridge now?' The participants also expressed that they had learned the importance of talking to the care recipient about matters in a more descriptive way when considering environmental changes. Instead of asking if the person wanted to move into a nursing home, they talked about the nursing home as a place where the person could be offered an apartment, where they could have very good food, activities and so on. They perceived that this way of talking about the unknown had a positive and calming effect.

The participants in the education programme expressed that they had increased their knowledge and understanding through the intervention and that it enabled them to focus on caring for persons with dementia. They became proud of their work and considered it as important. 'We have a local manager who encourages us to get the courses we want. You get confirmed, and you feel that you are on the right track', one of the care providers said. The participants highlighted the importance of being able to feel that they did a good job even while humble and sensitive to the care recipients and their individual needs.

\section{Relationship-building in order to provide good care}

The participants in the education program experienced the importance of building a good relationship as the key to approaching care recipients living with cognitive impairment. This conscious effort to build a good relationship seemed to result in an easier access to the care recipient's home which facilitated the provision of care. They expressed that it previously had 
been very difficult to gain access to the home. Building relationships as a key in the provision of good care was expressed by a care providers as follows:

It took six months to build a relationship with one care recipient that became so extensive that you could begin to help him with hygiene. In the beginning, you could go into the person's home bringing the newspaper and heating up his food, nothing personal. I can now see how the patient flourish, eats the food with good appetite. Last time I was there, it was difficult to get away from him. When you see that what you are doing really works, that the person is doing well, it strengthens me as a person. It's really great to see.

Another care provider said:

It becomes problematic when the care recipient requires many visits every day. He often says NO when care providers who do not know him as well as we do must come and help him. There is no problem when we come who know the care recipient.

The participants expressed that it takes time to build a relationship and really learn how to approach the patient. They found that they had to work differently with persons having dementia than with those having no cognitive impairment. A 'good' relationship is key to being able to develop and provide a care that works. 'The patient must recognize us and know who we are.' The participant continued, 'we begin with one care provider who works on entering the home and establish a stable relationship. Then we chose another one in the staff and starts to introduce that person.'

The participants also highlighted the importance of creating a good relationship with the relatives. They were aware of their intrusion into the home. A participant expressed this in the following manner: 
It's an intrusion into the home also for the relatives. We get to be a sounding board for the relatives; they get an outsider to talk to. To drink tea and have a small talk are very important. It is about building trust, of course we want to get to know their family, after a while it is very much appreciated when we come.

\section{Open and flexible approach conveys calm}

The participants in the education program reflected upon the importance of their own attitudes. They expressed the significance of having an open mind and an ability to sense the care recipient's mood. A positive attitude and the ability to convey a sense of calm was expressed as being crucial in the provision of care. They had the awareness that their mere presence was intrusive in the home. 'Even if I'm stressed, it is now easier for me to convey a sense of calmness. I do not know how I do it, but I just know that I can and that it affects the atmosphere in the home.' The care providers had become aware of how their own approach to each individual care recipient had relevance to and affected the atmosphere in the person's home.

A care provider reflects on the approach:

I never thought I would be able to work with persons with dementia. It's hard when you go from an "ordinary care unit" where there are a lot of procedures and a quick tempo to instead slow down and be sensitive to the care recipient's preferences. You should not tell them that you are stressed; it does not make anything go any faster. You should not talk about that you are in a hurry and stressed. If you got one hour you have to be there for an hour.

The participants talked about a changed approach that was more open and flexible in providing good care. One example of how this was carried out was when the care provider 
first took a moment to sit down with the care recipient and carried out a calm conversation for half an hour, before being able to help the person to shower without causing anxiety. This approach had been successful and had resulted in helping a care recipient to take a shower three times a week compared to once a month. The care providers experienced that they were able to create a sense of calmness in the encounters with the care recipients. This was conducted by an active strive to preserve the care recipient's personhood. The participants expressed that they believed that the care recipient's normal social behavior would last longer and that the time living at home could be prolonged.

\section{Continuity and flexibility are cornerstones in the care}

The participants expressed that there had been organizational changes since the education program started. This change was made to meet the needs of the necessary continuity and increased flexibility in order to build good relationships with the care recipients. The care provider expressed that this change helped them capture opportunities given in the moment. One example of this was when a care provider occasionally met a care recipient in the town. Since she could be flexible in work she invited the person to have lunch with her at the daycare center. The personnel had tried several times during the visits in the care recipient's home to invite the person with dementia to spend time at the daycare center, but without success. This opportunity to have lunch there together with the designated care provider helped the care recipient to take a decision built on own experience. This led to that the person started attending to the daycare center on a regularly basis. 
The participants expressed that it became easier for the care provider to work across boundaries and to do more for the care recipients. When their knowledge about the care recipient's needs increased, they became aware of their significance in the provision of care. This led to it becoming easier to make quick and rational decisions that supported the care recipients' health and well-being. An example of this was when the care providers made caring acts for the care recipients; they also focused on the relatives needs of participation and confirmation. The participants argued that this way of working also influenced the relationship between the care recipient and the relative in a positive way. They also expressed that this approach in the provision of care increased not only the cooperation in the home care staff group, but also between different professions.

This approach seemed to help the care providers to be able to focus and prioritize the most important things when a new care recipient was unwilling to receive care. They expressed that the provision of care started with building the caring relation and by ensuring continuity. This was done by introducing one to two persons from the staff to establish a relationship with the home care recipient and gradually start to carry out caring actions. The care manager provided the possibility by make special schedules for the staff. For example, in one local homecare area the staff was scheduled to create small work groups in order to ensure continuity and proper provision of care to home care recipients with dementia and other vulnerable persons. One care provider described: 'so that they feel they know us and recognize us - it has a huge importance- one patient only said a few words to begin with but can now say whole sentences.' The participants experienced that the home care recipients became more selfconfident and at the same time they expressed that they were more pleased with their own care work. 
A special group of care providers worked to cover up when the regular staff were on vacation, on sick leave etc. This group expressed that they tried to work with the same approach as the regular staff in the provision of care. They worked in the homecare services but also at the daycare center and in nursing homes. This led to that there already was a caring relationship initiated since the person moved between different forms of care. This was something the participants experienced especially important.

One of the challenges for the organization in being flexible was the time consuming scheduling. This was expressed to be especially important since there were many necessary considerations to be made. The organization with some of the care providers in small caring groups was challenging for the remaining staff, since they had to provide care to an increased number of care recipients in their daily work. This way of organizing provision of care was sometimes expressed as troublesome. It could sometimes be difficult to know whose responsibility the home care recipient was when a 'special home care group' was engaged. One example of this was expressed by a nurse:

It must be the whole package not social care, neither health care, nor regular home care or special home care. Sometimes the special home care groups live their own lives, cooperation can work but sometimes it doesn't. As nurse, I am not always informed.

In making decisions about the provision of care to a home care recipient, the nursing assistants and home care officers had to consider the predetermined care services in both content and time limit. For example, 4 minutes to make the bed, 15 minutes to help with personal hygiene 
and so on. To allow and provide the desired individual flexibility, the home care officers described that they made decisions that were not 'by the book': 'We try to go outside the box and not allow the computer program to control us'. They manually changed the predetermined time for each caring action in the program when necessary in order to make it possible to carry out the homecare services needed for the person with dementia. Decisions that comprised a prolongation of time were not comfortable for everyone in the home care staff and the participants expressed that the provided care service sometimes were questioned. Home care officers understood it as feelings of discomfort when the care providers only wanted to carry out home care service instead of spending time on building a relationship with the care recipient. However, the participants expressed they were aware that it takes time to change an approach. It seemed that it was slowly improving and becoming better and better. 'It has all happened in 5 years but we want to make it go even faster.' There was also a special type of homecare service called security visit. This type of service allowed the care providers to do something of significance for the care recipient, something that usually was not included in the home care service. This type of service was especially designed for persons with cognitive failure.

The new approach in the provision of care made the participants proud of their work. This was described by one of the participants as follows: 'we have come a long way, we are flexible to patient's needs. For example we have made a formal decision about that a person should be allowed to bring his cat when moving in to the nursing home. 'This kind of decision created a sense of security for the patient during the time waiting to move into a nursing home. 


\section{Perceived improvements}

The improvements identified among the care recipients were a significant increase in activities and decision making. The care recipients' health and nutritional status were improved and the move to a nursing home was postponed. According to the participants of this study the changed approach made it possible to establish a well-functioning homecare service much earlier among persons with dementia than previously. This became possible since the organization invested in an educational program focusing on building healthy relationships between care recipients with cognitive impairment and homecare personnel. The perception was that this increased the well-being among the care recipients, but also the care provider's feeling of work satisfaction.

According to the care managers there has been an increase in the amount of days the patients' remain at home. They expressed that before this change two-thirds of the care recipients with cognitive impairment were in need of moving to a nursing home. Their impression was that new care approach created by the education, postponed the transitions to the nursing home. Furthermore, they expressed that when care recipients now moved in to a nursing home they had a better nutritional status than a few years ago, which they interpreted as a clear sign of that the provision of homecare services have improved.

One participant expressed that the homecare staff in general had become more open and curious about what the care recipients were thinking and doing. The care providers push themselves into the person's world and tried to meet them in their situation. Participants described that they only need to guide the person back to the actual situation instead of taking over the situation, when the care recipient seemed to be lost. The aim of this new approach 
is to support the individual's sense of autonomy in everyday life. The home care recipient's involvement and autonomy seemed to increase. One example came from a participant who worked as a nurse. She described that the home care recipients were more engaged in the decisions and more motivated in the decision making to move to a nursing home. 'We do not work anymore with the law on compulsory psychiatric care and force! No one calls me the Dragon anymore'.

There were also signs that the care recipients were using less health care (primary and hospital). Different health problems were detected earlier and infections were prevented due to increased presence of homecare staff and such as improved personal hygiene.

\section{Discussion}

The experience of the education program in improving home care for persons with dementia is described in this study. Data were collected from all professions in the interventions: nurse's assistants, registered nurses, physiotherapists, occupational therapists, care managers, home care officers, politicians, management directors and two of the educators. The breadth of participants in this intervention and data collection conveys a broad perspective on how development of home care can be structured and the perceived outcomes of a program of education. Group interview as a method for collecting data, gave the participants' ability to reflect together which enables a deeper understanding the phenomenon (Berglund, Sjögren \& Ekebergh, 2012). The outcome of an intervention is influenced by many factors and can be investigated in several ways. The focus in this study is on the perspectives of care providers and decision makers in community based care without including the care recipients and their relatives. The area of interest has not been to measure the outcomes of the educational 
program. Instead, the focus for this investigation has been the experiences and perceptions of the phenomenon. The perspective RLR with lived experiences (Dahlberg, et al., 2008) has both benefits and limitations with lack of the benefits that a design with a before and after measurements can give.

The results indicate that the participants have obtained an increased awareness and understanding of persons with dementia and a new caring approach. Increased knowledge about the diseases and the use of the concept of cognitive impairment seemed to give a possibility to talk about problems in a more open way instead of being influenced of the stigma that can be set by using the word dementia. This is one of the keys in person-centered care which also has been highlighted by Edwards, Voss, and lliffe (2014). The findings in this study indicate that the participants became more attentive to signs of cognitive impairment. This knowledge seemed to increase the care provider's flexibility and their reflection concerning their own responsibility and their own significance in the person's situation. Altogether, this results in a care that is based on continuity that focuses on the individual's well-being, and gives the opportunity to be proud of working with persons with dementia.

Chrzescijanski et al. (2007) highlighted that education program can change staff attitudes and increase the attentiveness in how they perceive a person's feeling. This can help to improve the relationship between the person with dementia and staff which in fact can change both how the person reacts towards the staff and the possibility to provide care. This is similar to findings in this study that emphasize that increased knowledge about persons with dementia encourage care providers to deliberately strive to build a relationship that is grounded on reciprocity in order to provide good individual care. This has changed the staff's attitudes and 
caring approach to be more person-centered. According to (Tanner, 2013) this way of influencing the attitudes of staff and practices in a positive way in relation to persons with dementia plays a valuable role in increasing the possibility of living well with dementia. Furthermore, according to Tanner (2013) it aligns with an approach focusing on citizenship and personhood that involves recognising the individual's own capacity. This can be perceived as one key in the provision of person-centered care.

The project's origin was very clear to the management directors and the politicians. There was a clear intention to facilitate the ability for persons with dementia to have the same opportunities to remain in their homes as for persons without cognitive impairment. To provide this care for person's with dementia, an open and flexible approach that conveys calmness and security is necessary. Organizational changes were crucial to enable the new caring approach which led to improvement in the provision of home care on individual basis. This accomplishment requires that everyone involved in the care from such as decision making related to health issues to those who provide care are aware of the importance of continuity and flexibility in prioritizing the prerequisites in meeting the persons' needs. The education program seems to increase the involvement in everyday life by increasing the level of activity. Additionally, there are signs of improved health and a possibility to remain at home.

The participants experienced that the new knowledge became a part of the participant's way of caring. It influences the approach to all care recipients. The changes that this educational program stimulated can be understood not only on an intellectual level. It can also be understood as knowledge that has become situated and integrated in the body (Galvin \& Todres, 2009) as a new approach, a natural way of acting and caring for persons with dementia 
The engagement of the person as a whole increases the sense of own significance in the provision of care. This can be understood as a learning experience that is genuine and leads to real change supported by reflection (Ekebergh, 2007). To sustain this knowledge and keep this person-centered approach some of the care assistants became role models and were included in a network to bring the care further.

The conclusions in this study can be viewed as keys to improve person-centered homecare for persons with dementia and cognitive impairment are:

- Knowledge about cognitive impairment, dementia disease and person-centered care give competence to identify, discuss and deal with problems based on individual needs in the situation.

- A good relationship

- An open flexible and person-centered approach

- An organization that support continuity and flexibility in the provision of care for the care recipient

- A broad consensus on the aim of the care, from decision makers to care providers

- A program of education that is continuously ongoing and supports reflection upon the individual experience of caring. 


\section{References}

Berglund, M., Sjögren, R. \& Ekebergh, M. (2012). Reflect and learn together - when two supervisors interact in the learning support process of nurse education. Journal of Nursing Management. (29). 152-158.

Chrzescijanski, D., Moyle, W., \& Creedy, D. (2007). Reducing dementia-related aggression through a staff education intervention. Dementia, 6(2), 271-286. doi:doi:10.1177/1471301207080369

Cohen-Mansfield, J., Parpura-Gill, A., \& Golander, H. (2006). Utilization of Self-Identity Roles for Designing Interventions for Persons With Dementia. The Journals of Gerontology Series B: Psychological Sciences and Social Sciences, 61(4), P202-P212.

Cooke, M., Moyle, W., Venturato, L., Walters, C., \& Kinnane, J. (2014). Evaluation of an education intervention to implement a capability model of dementia care. Dementia, 13(5), 613-625. doi:doi:10.1177/1471301213480158

Dahlberg, H., \& Dahlberg, K. (2003). To not make definite what is indefinite. A phenomenological analysis of perception and its epistemological consequences. Journal of the Humanistic Psychologist, 31(4), 34-50. doi:10.1080/08873267.2003.9986933

Dahlberg, K., Dahlberg, H., \& Nyström, M. (2008). Reflective lifeworld research (2 ed.). Lund: Studentlitteratur.

Declaration of Helsinki. (2016). Ethical Principles for Medical Research Involving Human Subjects. Retrieved from http://www.wma.net/en/30publications/10policies/b3/

Edwards, R., Voss, S., \& Iliffe, S. (2014). Education about dementia in primary care: Is person-centredness the key? Dementia, 13(1), 111-119. doi:doi:10.1177/1471301212451381

Ekebergh, M. (2007). Lifeworld-based reflection and learning: a contribution to the reflective practice in nursing and nursing education. Reflective Practice, 8(3), 331343.

Ekman, I., Swedberg, K., Taft, C., Lindseth, A., Norberg, A., Brink, E., . . Sunnerhagen, K. S. (2011). Person-Centered Care - Ready for Prime Time. European Journal of Cardiovascular Nursing, 10(4), 248-251. doi:10.1016/j.ejcnurse.2011.06.008

Galvin, K. T., \& Todres, L. (2009). Embodying Nursing Openheartedness. Journal of Holistic Nursing, 27(2), 141-149. doi:doi:10.1177/0898010108323303

Gillsjö, C., \& Schwartz-Barcott D. (2011). A concept analysis of home and its meaning in the lives of three older adults. International Journal of Older People Nursing 6: 412.

Gillsjö, C., \& Schwartz-Barcott, D., \& von Post, I. (2011). Home: The place the older adult can not imagine living without. BMC Geriatrics 11: 10.

Hedman, A., Nygård, L., Almkvist, 0., \& Kottorp, A. (2015). Amount and type of everyday technology use over time in older adults with cognitive impairment. Scandinavian Journal of Occupational Therapy, 22(3), 196-206. doi:10.3109/11038128.2014.982172

Krueger, R., \& Casey, M. (2009). Focus Groups. A Practical Guide for Applied Research. (4 ed.). Thousand Oaks: Sage Publications.

Li, R., Cooper, C., Bradley, J., Shulman, A., \& Livingston, G. (2012). Coping strategies and psychological morbidity in family carers of people with dementia: A systematic 
review and meta-analysis. Journal of Affective Disorders, 139(1), 1-11.

doi:10.1016/j.jad.2011.05.055

Neal, M., \& Barton Wright, P. (2003). Validation therapy for dementia. Cochrane Database of Systematic Reviews(3). doi:10.1002/14651858.CD001394

Nordberg, G., Wimo, A., Jönsson, L., Kåreholt, I., Sjölund, B.-M., Lagergren, M., \& von Strauss, E. (2007). Time use and costs of institutionalised elderly persons with or without dementia: results from the Nordanstig cohort in the Kungsholmen Project-a population based study in Sweden. International Journal of Geriatric Psychiatry, 22(7), 639-648. doi:10.1002/gps.1724

O'Shaughnessy, M., Lee, K., \& Lintern, T. (2010). Changes in the couple relationship in dementia care. Dementia, 9(2), 237-258. doi:doi:10.1177/1471301209354021

Phinney, A., \& Chesla, C. A. (2003). The lived body in dementia. Journal of Aging Studies, 17(3), 283-299. doi:http://doi.org/10.1016/S0890-4065(03)00029-X

Rydholm Hedman, A.-M. (2007). Unequal opportunities for patients with and without cognitive impairment : relatives' and significant others' views on care and rehabilitation after hip fracture. Karolinska Institutet., Stockholm. Retrieved from http://urn.kb.se/resolve?urn=urn:nbn:se:rkh:diva-450

SBU. (2008). Dementia - Caring, ethics, ethnical and economical aspects: A systematic review. Stockholm: Statens beredning för medicinsk utvärdering

SFS. (2001:453). Socialtjänstlag. [Social Services Act]. Stockholm: Socialdepartementet.

SFS. (2003). Lag (2003:460) om etikprövning av forskning som avser människor.

Retrieved from https://www.riksdagen.se/sv/dokument-

lagar/dokument/svensk-forfattningssamling/lag-2003460-om-etikprovning-avforskning-som_sfs-2003-460.

Shanley, C., Russell, C., Middleton, H., \& Simpson-Young, V. (2011). Living through endstage dementia: The experiences and expressed needs of family carers. Dementia, 10(3), 325-340. doi:10.1177/1471301211407794

Sjöbäck, B. (1994). Aspects of quality and equality in dementia care. (Doctoral dissertation), Lund University, (2016:66)

Slaughter, S. E., Eliasziw, M., Morgan, D., \& Drummond, N. (2011). Incidence and predictors of eating disability among nursing home residents with middle-stage dementia. Clinical Nutrition, 30(2), 172-177. doi:10.1016/j.clnu.2010.09.001

Socialstyrelsen. (2014). Demenssjukdomarnas samhällskostnader i Sverige 2012 [Dementia diseases societal costs in Sweden in 2012]. Stockholm: Socialstyrelsen.

Socialstyrelsen. (2016). Nationella riktlinjer för vård och omsorg vid demenssjukdom [National Guidelines for Care in cases of Dementia]. Stockholm: Socialstyrelsen Retrieved from http://www.socialstyrelsen.se/Lists/Artikelkatalog/Attachments/20399/201611-7.pdf.

SOSFS. (1982:763). Hälso- och sjukvårdslag [Health and Medical Services Act]. Stockholm: Socialstyrelsen.

SOU. (2008:51). Värdigt liv i äldreomsorg. [Dignity in elderly care]. Stockholm: Socialdepartementet Retrieved from http://www.regeringen.se/rattsdokument/statens-offentligautredningar/2008/05/sou-200851/.

Sun, F. (2014). Caregiving stress and coping: A thematic analysis of Chinese family caregivers of persons with dementia. Dementia, 13(6), 803-818. doi:doi:10.1177/1471301213485593 
Svanström, R., \& Dahlberg, K. (2004). Living with dementia yields a heteronomous and lost existence. Western Journal of Nursing Research, 26(6), 671-687. doi:10.1177/0193945904265920 PMID:15359077

Svanström, R. (2009). När livsvärldens mönster brister-erfarenheter av att leva med demenssjukdom [When the lifeworld texture ruptures-experiences of living with dementia] ISBN: 978-91-7636-662-2. Linnaeus University Press, Växjö, Sweden.

Svanström, R., \& Sundler, A. J. (2015). Gradually losing one's foothold-a fragmented existence when living alone with dementia. Dementia, 14(2), 145-163. doi:10.1177/1471301213494510 PMID:24339094

Tanner, D. (2013). Identity, selfhood and dementia: messages for social work. European Journal of Social Work, 16(2), 155-170. doi:10.1080/13691457.2011.611795

Wadham, O., Simpson, J., Rust, J., \& Murray, C. (2016). Couples' shared experiences of dementia: a meta-synthesis of the impact upon relationships and couplehood. Aging \& Mental Health, 20(5), 463-473. doi:10.1080/13607863.2015.1023769 